Document downloaded from:

http://hdl.handle.net/10251/44537

This paper must be cited as:

Bermúdez, V.; Serrano, J.; Piqueras, P.; Garcia Afonso, O. (2013). Analysis of heavy-duty turbocharged diesel engine response under cold transient operation with a pre-turbo aftertreatment exhaust manifold configuration. International Journal of Engine Research. 14(4):341-353. doi:10.1177/1468087412457670.

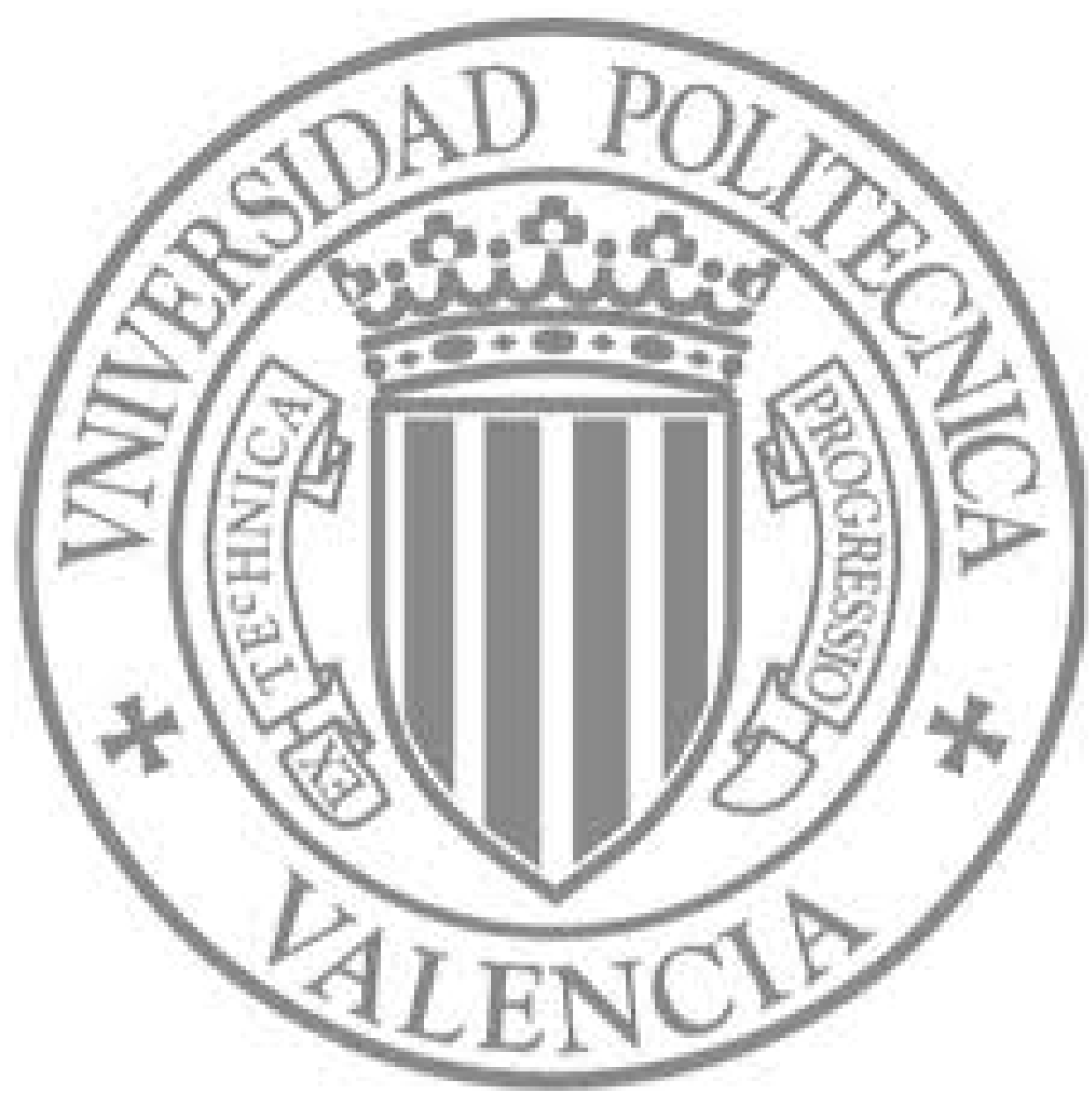

The final publication is available at

http://dx.doi.org/10.1177/1468087412457670

Copyright SAGE Publications (UK and US) 


\title{
Analysis of Heavy Duty turbocharged Diesel engine response under cold transient operation with a pre-turbo aftertreatment exhaust manifold configuration
}

\author{
V. Bermúdez, J.R. Serrano, P. Piqueras, O. García-Afonso
}

Universitat Politècnica de València, CMT - Motores Térmicos

\begin{abstract}
Diesel particulate filters are the most useful technology to reduce particulate matter from the exhaust gas of internal combustion engines. Although these devices have suffered an intense development in terms of the management of filtration and regeneration, the effect of the system location on the engine performance is still a key issue that needs to be properly addressed. The present work is focused on a computational study regarding the effects of a pre-turbo aftertreatment placement under full and partial load transient operation at constant engine speed and low wall temperature along the exhaust line.

The aim of the paper is to provide a comprehensive understanding of the engine response to define the guidelines of a control strategy able to get the standards of engine driveability during sudden accelerations under restraining thermal transient conditions governed by the aftertreatment thermal inertia. The proposed strategy overcomes the lack of temperature at the inlet of the turbine caused by the thermal transient by means of the boost and EGR control. It leads to properly manage the power in the exhaust gas for the expansion in the turbine.
\end{abstract}

\section{KEY WORDS}

Diesel engine; pre-turbo aftertreatment; transient operation; EGR control; boost control; gas dynamics.

\section{CONTACT INFORMATION}

Corresponding author: P. Piqueras. Universitat Politècnica de València, CMT - Motores Térmicos. Camino de Vera s/n, 46022 Valencia, Spain. Phone: +34 963877650 Fax: +34 963877659 e-mail: pedpicab@ mot.upv.es

\section{INTRODUCTION}

Nowadays, Diesel engines have become the most efficient propulsive system in automotive applications, both for passenger and heavy duty transport. Significant achievements in engine 
performance and emission reductions have been reached in the last years with because of studies regarding the injection [1] and combustion process [2], the understanding of transient operation [3][4] and pollutant formation during these phases [5][6], the turbocharging systems [7] or the exhaust gas recirculation [8]. However, the current and future emission regulations [9] demand very low levels of pollutant emissions that have led to an extensive implantation of aftertreatment devices along the exhaust line of Diesel engines [10].

Nowadays the diesel particulate filter (DPF) has become a required system in the case of particulate matter emissions. Even though the first developments on DPFs date back more than thirty years ago [11], the use of these devices has not been extended up to the last decade [12]. Usually, the DPF is placed downstream of the Diesel oxidation catalyst (DOC) to take advantage from the $\mathrm{NO}_{2}$ generation and the increase in temperature due to DOC exothermic chemical reactions. Nevertheless, passive regeneration occurrences are not frequent during actual engine operation and the need for active regeneration strategies arises leading to fuel consumption damage [13] besides that produced by the increasing back-pressure as the DPF is loaded.

Recent studies performed by Tourlonias and Koltsakis [13] points out the suitability of selective catalytic reduction (SCR) systems placed upstream the DOC and DPF for $\mathrm{NO}_{\mathrm{x}}$ reduction. However, this configuration damages passive regeneration and delays DOC lightoff causing an additional increase in fuel consumption.

These effects of the aftertreatment systems on engine performance can be mitigated under steady state operating conditions approaching for a pre-turbo placement of the DOC and the DPF. The analysis of exhaust manifold designs based on this kind of architecture is becoming widespread nowadays. Immediate advantages of these architectures are identified in terms of higher thermal level favouring passive regeneration occurrences in the DPF and enhancing the DOC light-off and conversion efficiency [14]. This kind of architecture reduces the pressure drop across the DPF because of the flow conditions upstream of the turbine [15]. Furthermore, the pre-turbo location of the DPF reduces the pumping losses due to the fact that the DPF pressure drop is not affected by the turbine expansion ratio to set the engine backpressure [16]. This improvement becomes more important as the DPF becomes loaded leading the engine performance to lower sensitive against soot loading [17]. The final effect of the pre-turbo aftertreatment placement on engine performance is also dependent on the management of heat losses across the aftertreatment system and the constant pressure turbocharging. The balance of these phenomena has been shown to be positive for the 
proposed pre-turbo aftertreatment configuration in several works and type of engines $[14][15][16]$. Other benefits derived from the pre-turbo DPF placement are: (i) a proper design of the filter packaging can allow it to act as isolator of interferences between the exhaust processes of consecutive firing order cylinders [16][18]; (ii) maximum EGR rate increase in heavy duty engines because of flow lamination [16]; (iii) clean high-pressure EGR; (iv) gas-urea mixing without swirl generators due to turbine swirl use in SCR; (v) possibility for EGR pre-cooling through an air gap surrounding the aftertreatment reducing also heat losses [19].

During transient operating conditions, the DPF thermal inertia appears as an additional aspect affecting the engine response. In fact, it becomes the key parameter controlling the time lapsus up to steady state performance. Depending on the wall temperature, the ceramic monoliths heat or cool the exhaust gases, imposing the final energy available for the expansion in the turbine. After engine operation at high load, the monolith walls are at high temperature. If the engine throttle is pushed down, the injected fuel mass is reduced and the temperature of the exhaust gases at the cylinders outlet decreases. However, the pre-turbo aftertreatment heats them increasing the energy available for the turbine. As a consequence, the turbocharger speed slight varies during this phase. This fact involves a decrease in turbocharger lag during the acceleration after zero-load periods [15]. By contrast, under cold exhaust wall conditions, the thermal inertia gives rise to a slow increase in energy available for the turbine during the load phase. Therefore, the engine response could be dramatically affected [17][20].

Under this context, the purpose of the present work is to analyse the effect of the pre-turbo DOC and DPF placement on a double-stage turbocharged heavy duty Diesel engine during transient operation under low wall temperature conditions by means of a computational study. The study covers the simulation of several full and partial load transient processes at constant engine speed. The transient processes are computed with different EGR opening timing and EGR rates in order to show their effects on the dynamic engine response.

The results confirm the negative influence of the greater thermal inertia under low wall temperature conditions. In terms of engine driveability, this negative effect of the thermal inertia can be mitigated modifying the boost and EGR control by increasing the maximum equivalence ratio temporally and delaying the obtaining of the target EGR rate. 


\section{MODELLING TOOLS AND METHODOLOGY}

The analysis of the engine transient response with a pre-turbo DOC and DPF exhaust manifold configuration has been performed trough a simulation-based study. The OpenWAM $^{\mathrm{TM}}$ resources [21][22] have been applied in this work. OpenWAM is an open source gas dynamic software for internal combustion engine modelling developed at CMTMotores Térmicos. The selected engine is a double-stage turbocharged heavy-duty Diesel engine, whose main characteristics are summarized in Table 1.

\section{TABLE 1}

The engine model has been tuned up from experimental data under steady state engine conditions at several engine speeds and under full-load transient operation at constant engine speed. Reference tests for model setup were performed with the original architecture of the exhaust line but without the aftertreatment elements.

The comparison between experimental and modelled results under steady-state engine conditions can be consulted in [16], where mean and instantaneous data are compared with very good agreement. Regarding the model setup for the simulation of the full-load transient tests at constant engine speed, experimental data from full-load transient tests at $1200 \mathrm{r} / \mathrm{min}$ and $1400 \mathrm{r} / \mathrm{min}$ are compared in Figure 1 with modelled results. A good reproduction of the engine dynamics is provided by the model. The EGR valve opening and the boost control were firstly integrated into OpenWAM as user functions to deal with transient process simulation. The original boost control system was simplified in the simulations. Hence the difference in injected fuel mass shown in Figure 1 at the beginning of the transient process while the EGR valve remains closed. The effects can be also observed in the torque prediction. Both the injected fuel mass and the engine torque are shown in Figure 1 normalised versus their maximum values respectively. The WG valve was kept fully closed during the tests being this setting applied in every simulation considered in the study. The communication between OpenWAM's core code and the control module was set every $0.02 \mathrm{~s}$. A technique to predict the combustion process during the transient process was also applied. It is based in an interpolation methodology from an engine database of the rate of heat release as a function of the crank angle and the engine operating conditions. The engine database, 
which represents the transient and steady operation range of the engine homogeneously, contains a set of RoHR defined by means of combined Wiebe's functions. The parameters defining the Wiebe's functions were obtained from a phenomenological parameterization of the RoHR [4], which was previously determined from the post-processing of the experimental in-cylinder pressure with a combustion diagnostic code [3].

\section{FIGURE 1}

\subsection{EXHAUST LINE ARCHITECTURES}

The work is focused on the comparison of the dynamic engine response as function of the aftertreatment system placement in the exhaust line, so that two configurations comprising the traditional post-turbo DOC and DPF configuration and a pre-turbo DOC and DPF architecture have been simulated.

The one-dimensional representation of the engine with the proposed pre-turbo aftertreatment configuration is sketched in Figure 2. The inclusion of the aftertreatment system upstream of the turbocharger involves an important increase in volume of the exhaust manifold. Such an increase upstream of the HPT leads to a reduction of the isentropic power available for the turbine expansion because of the degradation of the dynamic energy associated to the pressure pulses. Therefore, although this effect is less restrictive in pre-turbo DPF architectures than in post-turbo ones because of the location of the DPF pressure drop [16], the inlet and outlet volumes of the aftertreatment system have been optimized to preserve instantaneous kinetic energy as far as possible.

Additionally, the original DOC and DPF have been divided into two parallel branches and integrated as a part of the exhaust manifold, but keeping constant the catalyst (DOC) and filtration (DPF) surfaces of the original monoliths. Three cylinders discharge into each of these branches and the flow is conducted to the HPT after crossing the DPFs. This solution reduces the wave interferences between consecutive firing order cylinders resulting in the reduction of the pumping losses. On the other hand, the multifunctional exhaust manifold was insulated by means of a double wall with an air gap to reduce heat losses towards the environment.

The collection of the EGR mass flow in the case of the pre-turbo aftertreatment configuration is located between the DPF and the HPT. It allows obtaining clean high-pressure EGR avoiding the soot deposition along the EGR line. Furthermore, the pre-turbo DPF placement 
improves the instantaneous p3-p2 ratio. As a consequence, it is possible to obtain higher EGR rates for the same EGR valve opening [16].

\section{FIGURE 2}

\subsection{WALL-FLOW DPF CHARACTERISTICS}

The characteristics of the honeycomb wall-flow DPF used in the study are listed in Table 2. The only difference between the DPF monoliths used in the post-turbo and the pre-turbo aftertreatment configurations is that in the second case the original DPF has half of the length because of the division into two branches. The cylindrical cross section for every of the preturbo DPFs is kept the same than in the post-turbo case. The same criterion has been followed in the case of the DOCs.

The simulation of the DPF has been carried out by means of a model that solves the governing equations for one-dimensional compressible unsteady non-homentropic flow inside the monolith channels [23][24]. The formulation of the model for unsteady compressible flow is required for an appropriate description of the flow properties upstream of the turbine [15].

The inlet and outlet volumes of the aftertreatment have been modelled as OD elements, so that the effect of their specific geometry on the flow maldistribution at the inlet of the aftertreatment system has been neglected. Nevertheless, the monolith is discretised into several concentric channel beams to take into account the effect of the radial heat transfer on flow and substrate temperature. As the flow distribution at the inlet of the monolith is assumed to be homogeneous and the monolith cross section is cylindrical, the radial distribution of the flow properties inside the monolith is axi-symmetric. All the pairs of inlet and outlet channels in the same channel beam are assumed to have the same behaviour. Therefore, only one of them is solved by channel beam. The solution of the different concentric channel beams is coupled by means of the heat transfer model [25] which accounts for the gas to solid heat exchange in the monolith channels, the thermal inertia and the heat losses towards the environment.

\section{TABLE 2}




\subsection{SELECTION OF THE LOAD TRANSIENT PROCESSES}

High thermal inertia of the aftertreatment substrate is the most important characteristic explaining the good response in a consecutive tip-out and tip-in process of a turbocharged Diesel engine with pre-turbo aftertreatment architecture. The reason is that such a characteristic allows the substrate to heat the gas exhaust flowing through it leading to remove the turbocharger lag [15][17]. However, thermal inertia also becomes the parameter controlling the response of the engine in a tip-in process performed during the engine warmup or from low wall temperature in the exhaust line. In these cases, the exhaust gases are cooled down across the exhaust line and the pre-turbo placement of the aftertreatment severely limits the turbine inlet temperature.

In order to analyse the dynamic engine response under this kind of operating conditions, three load transient processes at constant engine speed have been defined as representative from those taking commonly place in the World Harmonized Transient Cycle (WHTC) [26]. The selected accelerations are characterized by the step in engine load 0-25\%, 0-75\% and 25-100 $\%$ at $1200 \mathrm{r} / \mathrm{min}$ as constant engine speed. This sort of accelerations is very common at many operating conditions in the WHTC, as Figure 3 shows. The thermal conditions for the simulations are set imposing the coolant temperature to $90{ }^{\circ} \mathrm{C}$ and the wall temperature in every element at the value taking place once reached the thermal stabilisation at the low initial engine load of every transient process. Regarding the aftertreatment simulation, the DPF is considered to be clean and the chemical reactions in the DOC and the DPF are not simulated in order to evaluate the engine dynamics in the worst situation. Nevertheless, other authors have already stated the low influence of chemical reactions on turbine inlet gas temperature during transient operation at low wall temperature in comparison with the restraining thermal inertia effect [20].

FIGURE 3

\section{RESULTS AND DISCUSSION}

Figure 4 shows the engine response for the post-turbo and pre-turbo aftertreatment configurations during a tip-in process from $0 \%$ to $75 \%$ in engine load at $1200 \mathrm{r} / \mathrm{min}$. The EGR valve at zero load is fully closed and it is opened to get an EGR rate equal to $20 \%$ once the $75 \%$ in engine load is reached. The setting time for the EGR valve opening is the same in 
all simulations of Figure 4, i.e. it is opened $0.75 \mathrm{~s}$ after the tip-in beginning. The maximum equivalence ratio allowed by the boost control during the acceleration has been set to the maximum value reached in the case of the post-turbo aftertreatment architecture. Applying these settings, the engine response with a pre-turbo DOC and DPF placement is clearly damaged, as it is shown in Figure 4(a), which represents the evolution of the normalised engine torque along the transient process. The aftertreatment thermal inertia causes a low rate of HPT inlet temperature rise shown in plot (d) from Figure 4. As a consequence, the turbocharger speed and associated variables, like air mass flow shown in Figure 4(b), increase slowly. This response is worsened when the EGR valve is opened, since it leads the air mass flow to an instantaneous decrease. As the energy available for the expansion in the HP and LP turbines increases, the turbocharger speed also goes up leading to a slow recovery of the air mass flow and the intake pressure. This process feeds back the fuel mass injection that is dependent on the air mass flow through the boost control in order to keep constant the equivalence ratio, which is represented in Figure 4(c). The injected fuel mass reaches its target value when the equivalence ratio begins to decrease about second 32 in Figure 4(c).

\section{FIGURE 4}

Strategies to reach the target torque without compromising engine driveability must be focused on the increase in power available at the inlet of the turbines during the beginning of the transient process. The solution demands a proper setup of the air management control parameters. In this way, the WG valve of the HP turbine must be kept closed during the transient process. In this study, this strategy is already applied in the reference simulation with post-turbo DOC and DPF configuration. An additional alternative to improve the engine dynamics lies on the set up of less restrictive limits on equivalence ratio during transient periods since smoke emission peaks to the atmosphere will be avoided by the DPF filtration. A maximum equivalence ratio equal to 1 has been allowed in every simulation both for postturbo and pre-turbo aftertreatment placements. Finally, the EGR opening timing can be managed to control its damaging effect on the engine transient dynamics.

In the case of a sudden EGR opening strategy (taking place with a duration of $0.5 \mathrm{~s}$ in this work), an air mass flow decrease of high magnitude will be produced almost instantaneously. Consequently, the EGR opening should be delayed in order to not affect the engine 
performance in the case of a pre-turbo aftertreatment placement. Figure 5 compares the engine response of the post-turbo and the pre-turbo aftertreatment configurations for a tip-in process from $0 \%$ to $75 \%$ in engine load at $1200 \mathrm{r} / \mathrm{min}$. In the case of the pre-turbo aftertreatment configuration, three engine responses in which the EGR valve is opened at different times are shown. The earliest EGR opening has been carried out $0.75 \mathrm{~s}$ after the beginning of the tip-in process, as it can be observed in the air mass flow response show in plot (b) from Figure 5. It coincides with the EGR opening in the case of the post-turbo aftertreatment configuration. In this case, the pre-turbo aftertreatment configuration is damaged in transient torque and bsfc as Figure 5(a) and (c) show respectively. The air mass flow diminishes up to $0.175 \mathrm{~kg} / \mathrm{s}$ reducing further the power available for the turbines expansion. It makes not possible to inject the maximum fuel mass since the maximum allowed equivalence ratio is reached, as it is depicted in Figure 5(d). As a consequence, the engine dynamics becomes again governed by the aftertreatment thermal inertia. Finally, the maximum injected fuel mass is reached from time $19 \mathrm{~s}$ (16 s after the tip-in beginning).

The setting time of the EGR valve opening that does not produce the engine torque fall down has been found $2.75 \mathrm{~s}$ after the tip-in beginning. The application of this strategy contributes to a faster engine response although it causes a transient increase in bsfc of about $5 \%$ (Figure $5(c))$ with respect to the post-turbo aftertreatment configuration and can give rise to a NOx emission peak wider in time.

In the case of the post-turbo aftertreatment configuration and after the first seconds of the transient process, the flow properties are subjected to a quasi-steady phase managed by the exhaust manifold and turbocharger thermal inertia. The time response of the different magnitudes shows a decrease in the initial slope but it remains leading to a progressive decrease in bsfc, as Figure 5(c) shows. A similar response is found in the case of the pre-turbo aftertreatment configuration. Any the opening time of the EGR valve, the engine response becomes finally quasi-steady and the thermal transient in the multi-functional exhaust manifold controls the convergence towards steady state conditions.

\section{FIGURE 5}

Figure 6 represents the gas temperature evolution between the inlet and the outlet of the aftertreatment system. The inlet aftertreatment temperature, which is represented in Figure 
6(a) by the dashed lines, gets almost stable around time $30 \mathrm{~s}$ in the case of the pre-turbo aftertreatment configuration. The thermal stabilization at the inlet of the aftertreatment produces the following slight reduction of the HPT inlet temperature. The reason is the high thermal inertia of the aftertreatment substrate. Figure 6(b) shows the gas and substrate wall temperature in the outlet cross-section of the DPF both in the core and the peripheral region of the monolith. As the transient makes progress, both the gas and substrate temperature increase across the monolith core. In this region, the gas temperature at the outlet of the DPF converges to the aftertreatment inlet temperature at time $25 \mathrm{~s}$. This time defines the maximum HPT inlet temperature, which is shown in Figure 6(a). The temperature begins to decrease from this instant to finally become equal to the substrate temperature. It marks the end of the thermal transient in this region of the monolith because of the gas to wall temperature gradient, what implies the end of the main transient effects on the engine response.

FIGURE 6

However, the substrate wall temperature in the monolith periphery has scarcely increased since the tip-in beginning, as Figure 6(b) shows. It explains the outlet gas temperature decrease in the monolith core in spite of the constant gas temperature at the inlet of the DPF. The conductive radial heat transfer [25] is governing this temperature decrease that finally produces the gas temperature drop at the HPT inlet shown in Figure 6(a).

The consequence is the reduction of the available power for the turbine expansion. It produces a slight decrease in the turbocharger speed shown in Figure 7(d) from time 30 s. It gives rise to the corresponding decrease in boost and HPT inlet pressure, which are shown in plots (c) and (b) from Figure 7. In turn, this transient evolution results in a slight air mass flow reduction that increase the equivalence ratio, as it is shown in plots (b) and (d) from Figure 5. Therefore, the decrease in air mass flow will lead to a new increase in HPT inlet temperature. Thus, a slow second order stabilization process begins being its dynamics mainly controlled by the aftertreatment thermal inertia and hence the peripheral wall temperature convergence.

FIGURE 7 
A sudden early opening of the EGR valve in the case of the post-turbo aftertreatment configuration has an advantage in terms of reduction of NOx emission peak at the beginning of the tip-in process. However, this kind of strategy does not seem to work effectively in the case of a pre-turbo aftertreatment configuration due to the possible damage on engine torque. Figure 8(a) shows an example of the engine torque response for the tip-in process at 1200 $\mathrm{r} / \mathrm{min}$ from $0 \%$ to $75 \%$ in engine load including a slow opening of the EGR valve in the case of the pre-turbo aftertreatment placement. This strategy allows also moving forward the EGR valve opening up to the same setting time than in the case of a post-turbo aftertreatment configuration being possible to preserve the engine torque. The slow EGR valve opening reduces the rate of air mass flow decrease so that the injected fuel mass is not affected and hence the engine torque. Additionally, the early EGR valve opening with a progressive EGR rate increase should contribute to reduce the transient NOx emission peak. In the transient process shown in Figure 8(b), when a slow EGR opening strategy is applied to the pre-turbo aftertreatment configuration the target EGR rate is reached $4.25 \mathrm{~s}$ after the beginning of the valve opening.

\section{FIGURE 8}

Figure 9 represents the tip-in process from $25 \%$ to $100 \%$ in engine load at $1200 \mathrm{r} / \mathrm{min}$. The beginning of the transient acceleration from a partial low load provides an important reduction of the duration of the first phase of the thermal transient, i.e. up to the instant in which the HPT inlet temperature reaches a quasi-steady value. Figure 9(d) shows that this temperature stabilizes around time $12 \mathrm{~s}$, whereas in the previously shown tip-in process from $0 \%$ to $75 \%$ in engine load this time was $25 \mathrm{~s}$ (Figure 6(a)).

\section{FIGURE 9}

At $25 \%$ in engine load the EGR rate is $20 \%$, so that the EGR valve is suddenly fully closed at the beginning of the acceleration. It is again opened $0.75 \mathrm{~s}$ after in the case of the post-turbo aftertreatment configuration. However, the opening has to be delayed when the pre-turbo aftertreatment placement is considered. The delay time must be at least $1.9 \mathrm{~s}$ to avoid any effect on the engine torque, as Figure 9(a) shows. Nevertheless, this delay is lower than in the 
case of the tip-in process from $0 \%$ to $75 \%$ in engine load, in which the required delay with a sudden EGR opening was $2.75 \mathrm{~s}$. The reason lies again in the benefits of starting the tip-in process from a stabilized partial low load. At the beginning of the acceleration, Figure 9(b) shows that the initial engine load and the sudden EGR closing gives rise to a high rate in air mass flow increase. It and the maximum allowed equivalence ratio equal to 1 (Figure 9(c)) result in the ability to inject the target fuel mass since the beginning of the transient. This fact improves the engine dynamics because of the increase in power available for the turbine expansion. Another consequence of the maximum equivalence ratio is the temperature peak at the inlet of the aftertreatment system shown in Figure 9(d), which reaches $850{ }^{\circ} \mathrm{C}$. The indicated high rate of mass flow increase produces a fast reduction of gas temperature towards its steady value around $550{ }^{\circ} \mathrm{C}$ at the inlet of the aftertreatment system. It marks the end of the main phase of the aftertreatment thermal transient as occurred in the previous analysed tip-in process from $0 \%$ to $75 \%$ in engine load.

The reduction of the required EGR rate allows an early sudden EGR opening without damaging the engine torque. Figure 10 shows the first phase of the transient process governed by the aftertreatment thermal inertia for EGR rates $15 \%, 10 \%$ and $0 \%$ during a load transient from $25 \%$ to $100 \%$. A sudden EGR opening taking place at the same time independently of the exhaust architecture is possible with a target EGR rate below $15 \%$, without any effect on engine torque. Anyway, the aftertreatment thermal transient governs the thermodynamic response so that consequently the engine operates at a higher equivalence ratio decreasing along the time. Nevertheless, results in Figure 10 clearly point out that the differences are reduced as the EGR rate requirement is lower.

\section{FIGURE 10}

Figure 11 shows the engine response in the case of a tip-in process from $0 \%$ to $25 \%$ in engine load at $1200 \mathrm{r} / \mathrm{min}$. In this case, the EGR valve is initially fully closed and is opened at the same instant that the acceleration begins. This strategy represents the most restrictive one both for the post-turbo and the pre-turbo aftertreatment placements. However, Figure 11(a) confirms that both configurations are able to reach the target engine torque instantaneously. In the case of the pre-turbo aftertreatment configuration, the initial air mass flow decrease because of the early EGR valve opening (Figure 11(b)). The slow increase in HPT inlet 
temperature because of the thermal inertia (Figure 11(d)) leads to a transient rise of the equivalence ratio, as represented in Figure 11(c). This increase finishes once the air mass flow begins its recovery, which is reached due to the positive feedback caused by the progressive heating of the aftertreatment substrate. In any case, a delay of the EGR valve opening or a slow opening would contribute to improve further the dynamics of the engine response getting earlier the quasi-steady HPT inlet temperature.

\section{FIGURE 11}

Once proved the capability to recover the engine driveability with a proper boost and EGR control, it is important to highlight the effect on the bsfc at the beginning of the tip-in process. Figure 12 shows a comparison between the dimensionless bsfc obtained with post-turbo and pre-turbo aftertreatment placement in tip-in processes at $1200 \mathrm{r} / \mathrm{min}$ and different load step under low exhaust wall temperature conditions. These results allow concluding that the preturbo aftertreatment placement leads to a transient increase of the bsfc, whose duration and magnitude is higher as the delay in EGR valve opening delay increases. However, once the EGR valve is opened, the bsfc of the pre-turbo aftertreatment configuration converges to the same level than in the case of the post-turbo aftertreatment architecture.

\section{FIGURE 12}

\section{SUMMARY AND CONCLUSIONS}

A computational study of a heavy duty Diesel engine equipped with a pre-turbo aftertreatment exhaust manifold has been presented in this paper focused on the analysis of the engine response under transient operation and cold wall temperature conditions. The importance of a properly control of the transient maximum equivalence ratio and the management of the EGR valve opening to keep engine driveability with respect to traditional post-turbo aftertreatment placement have been addressed.

The study has been performed on the basis of a multi-functional exhaust manifold including a pre-turbo placement of the DOC and DPF, the collection of clean high pressure EGR and a thermal insulation of the whole system by means of an air gap. The advantages of this kind of system under steady state operation have been already discussed in the literature, in which is emphasized the advantages in terms of engine performance because of the lower engine back- 
pressure and the increase in mean thermal level of the aftertreatment favouring the DPF passive regeneration and the DOC light-off and conversion efficiency.

With respect to transient operation, the thermal inertia of the aftertreatment is the main phenomenon conditioning the engine response. Under hot wall temperature operation, the substrate acts as a heat source during decelerations keeping turbocharger speed quasiconstant. However, during warm-up engine conditions or after being the engine operating in a quasi-steady state at partial low load, the substrate thermal inertia shift the inlet turbine temperature in next tip-in processes. The calculations and analysis performed in this work have proved that the engine driveability can be preserved with a pre-turbo aftertreatment configuration without high influence on the specific fuel consumption by means of a proper management of the boost and EGR control; i.e. allowing transient equivalence ratios equal or even higher than stoichiometric conditions and applying suitable settings for the EGR valve opening.

In the case of the EGR valve opening, it has been shown that a late sudden opening or an early progressive opening allow getting faster stable conditions regarding engine torque. Nevertheless, the final setting should be a balance between driveability and transient NOx emissions. In fact, driveability should be understood not only regarding isolate tip-in processes but actual driving conditions in which a series of tip-in \& tip-out processes are expected. As in these situations thermal transient is not sure to be completed, the previous history would determine the conditions in which the target torque can be reached. Taking into account the well-known behaviour of opposite transient operation defined by hot or cold wall temperature, actual driving conditions will be generally an intermediate state. Therefore, it is expected that tip-out phases will be favoured by the capability of the engine to keep quasiconstant the turbocharger speed removing or reducing the turbocharger lag in following tip-in processes. In turn, this will involve good initial conditions to face the thermal transient of the substrate defined by the engine load step but dependent on the previous engine operation, which will determine the control requirements. 


\section{ACKNOWLEDGMENTS}

This work has been partially supported by the Universitat Politècnica de València through grant number INNOVA 2011-3182.

\section{NOTATION}

$\begin{array}{ll}\text { bsfc } & \text { brake specific fuel consumption } \\ \text { DOC } & \text { Diesel oxidation catalyst } \\ \text { DPF } & \text { Diesel particulate filter } \\ \text { EGR } & \text { exhaust gas recirculation } \\ \text { HDD } & \text { heavy-duty Diesel } \\ \text { HP } & \text { high pressure } \\ \text { HPC } & \text { high pressure compressor } \\ \text { HPT } & \text { high pressure turbine } \\ \text { LP } & \text { low pressure } \\ \text { LPC } & \text { low pressure compressor } \\ \text { LPT } & \text { low pressure turbine } \\ \text { NOx } & \text { nitrogen oxides } \\ \text { RoHR } & \text { rate of heat released } \\ \text { SCR } & \text { selective catalytic reduction } \\ \text { WG } & \text { waste-gate } \\ \text { WHTC } & \text { World Harmonized Transient Cycle }\end{array}$

\section{REFERENCES}

1. Payri F, Pastor JV, Pastor JM and Juliá JE. Diesel spray analysis by means of planar laser-induced exciplex fluorescence. Int. J. of Engine Res. 2006; 7(1): 77-89.

2. Torregrosa AJ, Broatch A, Margot X, Marant V and Beauge Y. Combustion chamber resonances in direct injection automotive Diesel engines: a numerical approach. Int. J. of Engine Res. 2004; 5(1): 8391.

3. Serrano JR, Arnau FJ, Dolz V and Piqueras P. Methodology for characterisation and simulation of turbocharged diesel engines combustion during transient operation. Part 1: Data acquisition and postprocessing. Applied Thermal Engineering 2009; 29(1): 142-149.

4. Serrano JR, Climent H, Guardiola C and Piqueras P. Methodology for characterisation and simulation of turbocharged diesel engines combustion during transient operation. Part 2: Phenomenological combustion simulation. Applied Thermal Engineering 2009; 29(1): 150-158.

5. Rakopoulos CD, Dimaratos AM, Giakoumis EG, Rakopoulos DC. Evaluation of the effect of engine, load and turbocharger parameters on transient emissions of Diesel engine. Energy Conversion and Management 2009; 50(9):2381-93.

6. Rakopoulos CD, Dimaratos AM, Giakoumis EG, Rakopoulos DC. Investigating the emissions during acceleration of a turbocharged Diesel engine operating with bio-diesel or n-butanol diesel fuel blends. Energy 2010; 35(12):5173-84. 
7. Ishikawa N. A study on emissions improvement of a diesel engine equipped with a mechanical supercharger. Int. J. of Engine Res. 2012; 13(2): 99-107.

8. Desantes JM, Luján JM, Pla B and Soler JA. On the combination of high-pressure and low-pressure exhaust gas recirculation loops for improved fuel economy and reduced emissions in high-speed directinjection engines. Int. J. of Engine Res. 2021, doi: 10.1177/1468087412437623.

9. Regulation (EC) $n^{\circ} 715 / 2007$ of the European Parliament and of the Council of 20 June 2007 on type approval of motor vehicles with respect to emissions from light passenger and commercial vehicles (Euro 5 and Euro 6) and on access to vehicle repair and maintenance information. Official Journal of the European Union, June 2007.

10. Johnson TV. Review of diesel emissions and control. Int. J. of Engine Res. 2009; 10(5): 275-285.

11. Howitt J and Montierth M. Cellular ceramic diesel particulate filter. SAE technical paper 81104, 1981.

12. Salvat $\mathrm{O}$, Marez $\mathrm{P}$ and Belot G. Passenger car serial application of a particulate filter system on a common-rail, direct-injection diesel engine. In: SAE Technical Paper 2000-01-0473, 2000.

13. Tourlonias $\mathrm{P}$ and Koltsakis G. Model-based comparative study of Euro 6 diesel aftertreatment concepts, focusing on fuel consumption. Int. J. of Engine Res. 2011; 12(3): 238-251.

14. Joergl V, Keller P, Weber O, Mueller-Hass K and Konieczny R. Influence of pre-turbo catalyst design on Diesel engine performance, emissions and fuel economy. In: SAE Technical Paper 2008-01-0071.

15. Bermudez V, Serrano JR, Piqueras P and García-Afonso O. Assessment by means of gas modelling of a pre-turbo Diesel particulate filter configuration in a turbocharged HSDI Diesel engine under full-load transient operation. Proceedings of the Institution of Mechanical Engineers, Part D: Journal of Automobile Engineering 2011; 225(9): 1134-1155.

16. Payri F, Serrano JR, Piqueras P and García-Afonso O. Performance analysis of a turbocharged heavy duty Diesel engine with a pre-turbo Diesel particulate filter configuration. SAE International Journal of Engines 2011; 4(2): 2559-2575.

17. Bermudez V, Serrano JR, Piqueras P and García-Afonso O. Influence of DPF soot loading on engine performance with a pre-turbo aftertreatment exhaust line. In: SAE Technical Paper 2012-01-0304, 2012.

18. Payri F, Desantes JM, Piqueras P, Serrano JR. Dispositive for treatment of exhaust gases of Diesel turbo-supercharged internal combustion engines. Patent application P201131537, 2011.

19. Payri F, Desantes JM, Galindo J, Serrano JR. Exhaust manifold of a turbocharged reciprocating internal combustion engine. Patent application WO 2010/092201 A1, 2010. 
20. Subramaniam MN, Joergl V, Keller P, Weber O, Toyoshima T and Vogt CD. Feasibility assessment of a pre-turbo after-treatment system with a 1D modelling approach. In: SAE Technical Paper 2009-01$1276,2009$.

21. Openwam website, CMT-Motores Térmicos (Universitat Politècnica de València). www.openwam.org, 2012.

22. Galindo J, Serrano JR, Arnau FJ, Piqueras P. Description of a Semi-Independent Time Discretization methodology for a one-dimensional gas dynamics model. Journal of Engineering for Gas Turbines and Power 2009; 131: 034504.

23. Torregrosa AJ, Serrano JR, Arnau FJ and Piqueras P. A fluid dynamic model for unsteady compressible flow in wall-flow diesel particulate filters. Energy 2011;36: 671 - 684.

24. Desantes JM, Serrano JR, Arnau, FJ and Piqueras P. Derivation of the method of characteristics for the fluid dynamic solution of flow advection along porous wall channels, Applied Mathematical Modelling 2012;36:3134-3152.

25. Galindo J, Serrano JR, Piqueras P and García-Afonso O. Heat transfer modeling in wall-flow diesel particulate filters, Energy 2012;43(1):201-213.

26. Emission Test Cycles. Dieselnet website. http://www.dieselnet.com/standards/cycles/whtc.php, 2012.

\section{LIST OF TABLES}

Table 1.- Basic engine characteristics.

Table 2.- Geometrical specifications of the DPF.

\section{LIST OF FIGURES}

Figure 1.- Comparison between experimental data and modelled results under full-load transient operation at $1200 \mathrm{r} / \mathrm{min}$ and $1400 \mathrm{r} / \mathrm{min}$.

Figure 2.- Engine scheme in OpenWAM's interface: pre-turbo DOC and DPF configuration.

Figure 3.- Simulated transient processes present at different phases of the World Harmonized Transient Cycle. 
Figure 4.- Tip-in at $1200 \mathrm{r} / \mathrm{min}$ from $0 \%$ to $75 \%$ in engine load applying the same setting for EGR valve opening timing and maximum equivalence ratio.

Figure 5.- Tip-in at $1200 \mathrm{r} / \mathrm{min}$ from $0 \%$ to $75 \%$ in engine load. Effect on engine performance of increase in maximum equivalence ratio and different EGR opening timing with a pre-turbo DOC and DPF architecture.

Figure 6.- Tip-in at $1200 \mathrm{r} / \mathrm{min}$ from $0 \%$ to $75 \%$ in engine load. Thermal transient in the DPF with a pre-turbo DOC and DPF configuration.

Figure 7.- Tip-in at $1200 \mathrm{r} / \mathrm{min}$ from $0 \%$ to $75 \%$ in engine load. HP turbocharger response as function of the exhaust manifold architecture.

Figure 8.- Tip-in at $1200 \mathrm{r} / \mathrm{min}$ from $0 \%$ to $75 \%$ in engine load. Effect of EGR slow opening on engine torque and air mass flow.

Figure 9.- Tip-in at $1200 \mathrm{r} / \mathrm{min}$ from $25 \%$ to $100 \%$ in engine load. Effect on engine response of a pre-turbo aftertreatment configuration.

Figure 10.- Tip-in at 1200 r/min from $25 \%$ to $100 \%$ in engine load. Effect on engine response of a pre-turbo aftertreatment configuration under different EGR rate at steady state operation.

Figure 11.- Tip-in at $1200 \mathrm{r} / \mathrm{min}$ from $0 \%$ to $25 \%$ in engine load. Effect on engine response of a pre-turbo aftertreatment configuration.

Figure 12.- Effect of pre-turbo aftertreatment configuration on bsfc during the different tip-in processes at $1200 \mathrm{r} / \mathrm{min}$.

Table 1.- Basic engine characteristics.

\begin{tabular}{|l|l|}
\hline Type of engine & Double-stage turbocharged HDD engine \\
\hline Engine swept volume & $10836 \mathrm{~cm}^{3}$ \\
\hline Number of cylinders & 6 \\
\hline Stroke & $152 \mathrm{~mm}$ \\
\hline Bore & $123 \mathrm{~mm}$ \\
\hline Connecting Rod & $255 \mathrm{~mm}$ \\
\hline Compression ratio & $16: 1$ \\
\hline Turbocharger & WG HP turbine + LP turbine \\
\hline
\end{tabular}


Table 2.- Geometrical specifications of the DPF.

\begin{tabular}{|c|c|c|}
\hline & Post-turbo placement & Pre-turbo placement \\
\hline Length $[\mathrm{m}]$ & 0.3 & $2 \times 0.15$ \\
\hline Diameter $[\mathrm{m}]$ & 0.27 & 0.27 \\
\hline Cell density $[\mathrm{cpsi}]$ & 100 & 100 \\
\hline Filter cell size $[\mathrm{mm}]$ & 2.1 & 2.1 \\
\hline Wall thickness [mm] & 0.43 & 0.43 \\
\hline Permeability $\left[\mathrm{m}^{2}\right]$ & $1.8 \times 10^{-3}$ & $1.8 \times 10^{-3}$ \\
\hline Filtration area $\left[\mathrm{m}^{2}\right]$ & 11.1 & $2 \times 5.55$ \\
\hline
\end{tabular}
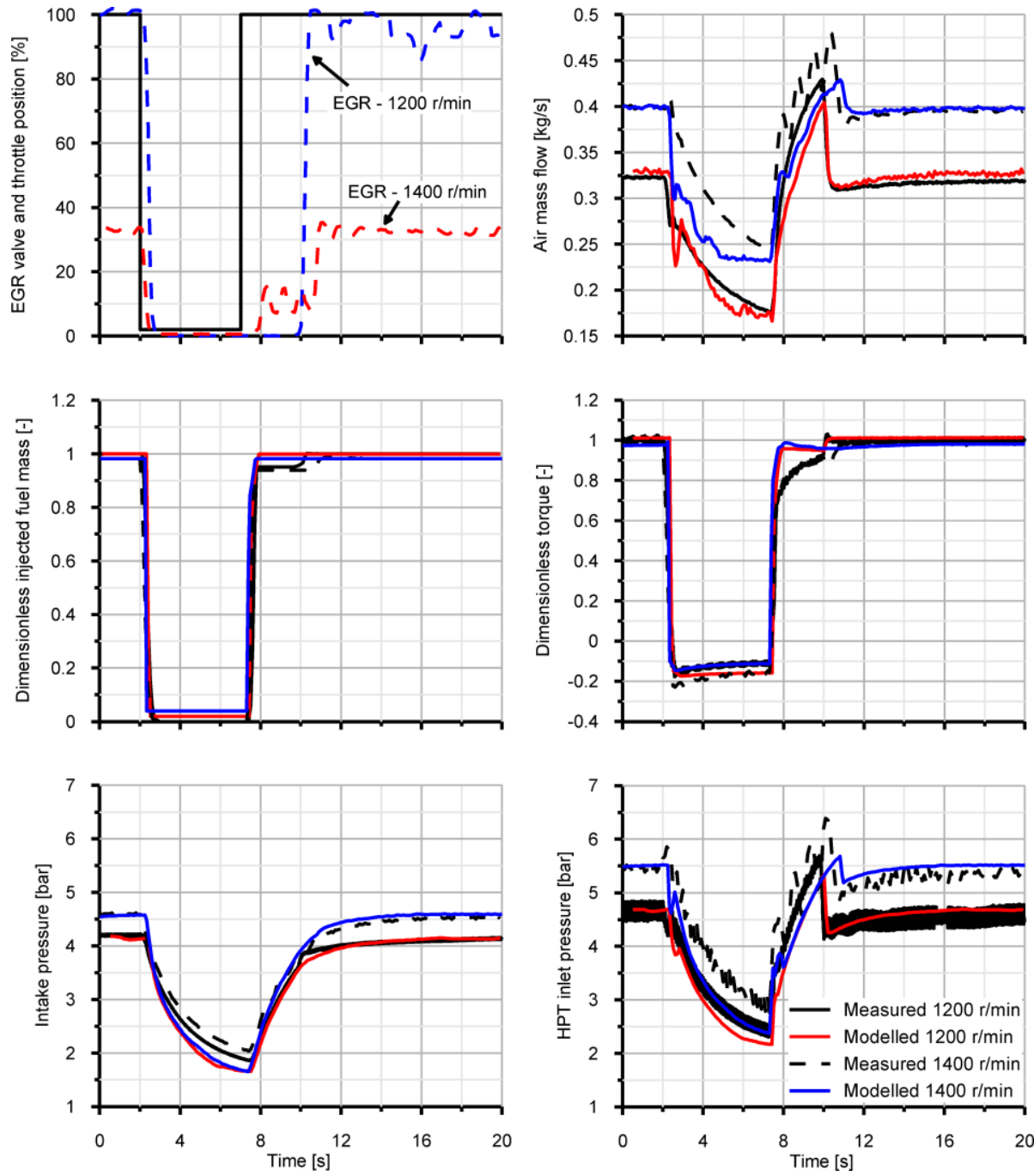

Figure 1.- Comparison between experimental data and modelled results under full-load transient operation at $1200 \mathrm{r} / \mathrm{min}$ and $1400 \mathrm{r} / \mathrm{min}$. 


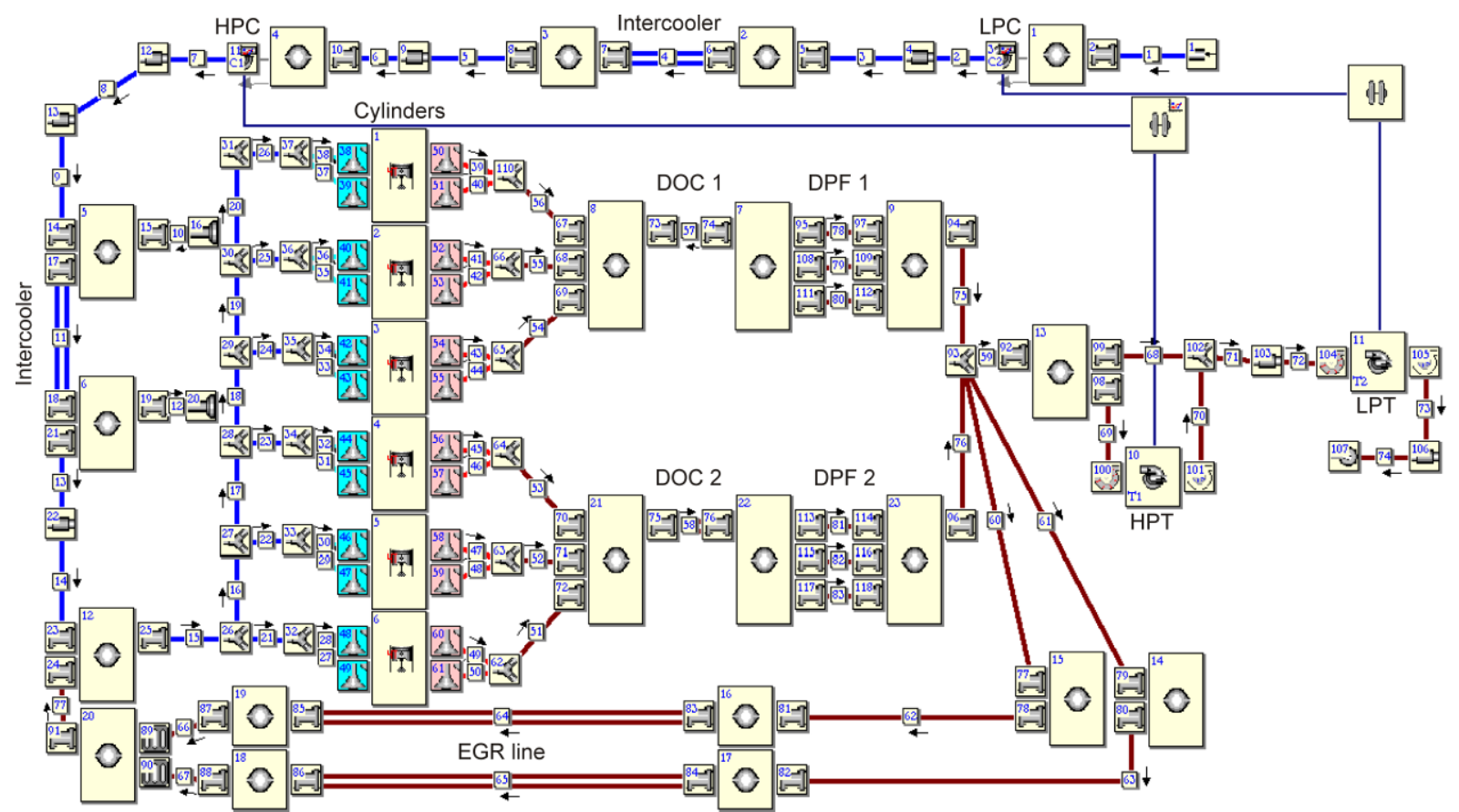

Figure 2.- Engine scheme in OpenWAM's interface: pre-turbo DOC and DPF configuration.
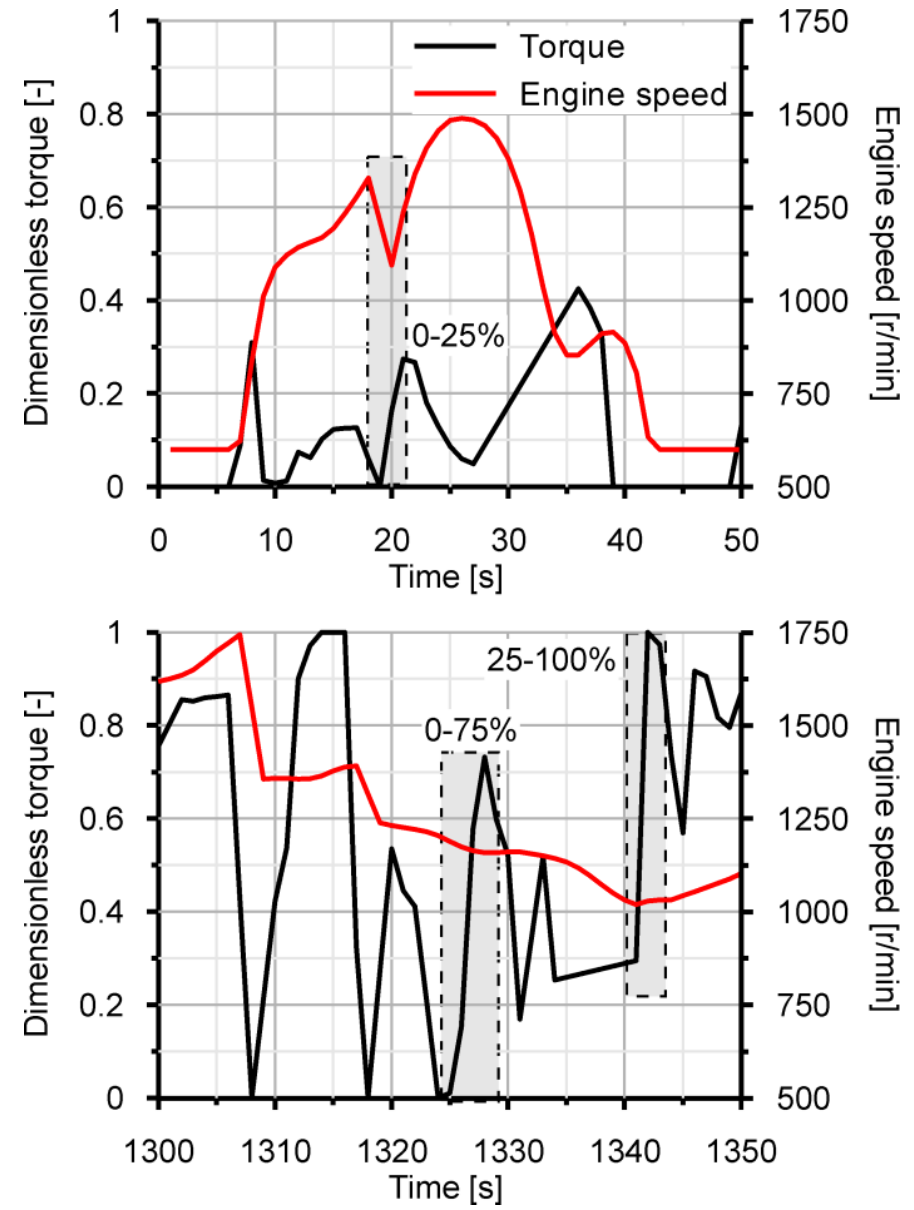

Figure 3.- Simulated transient processes present at different phases of the World Harmonized Transient Cycle. 

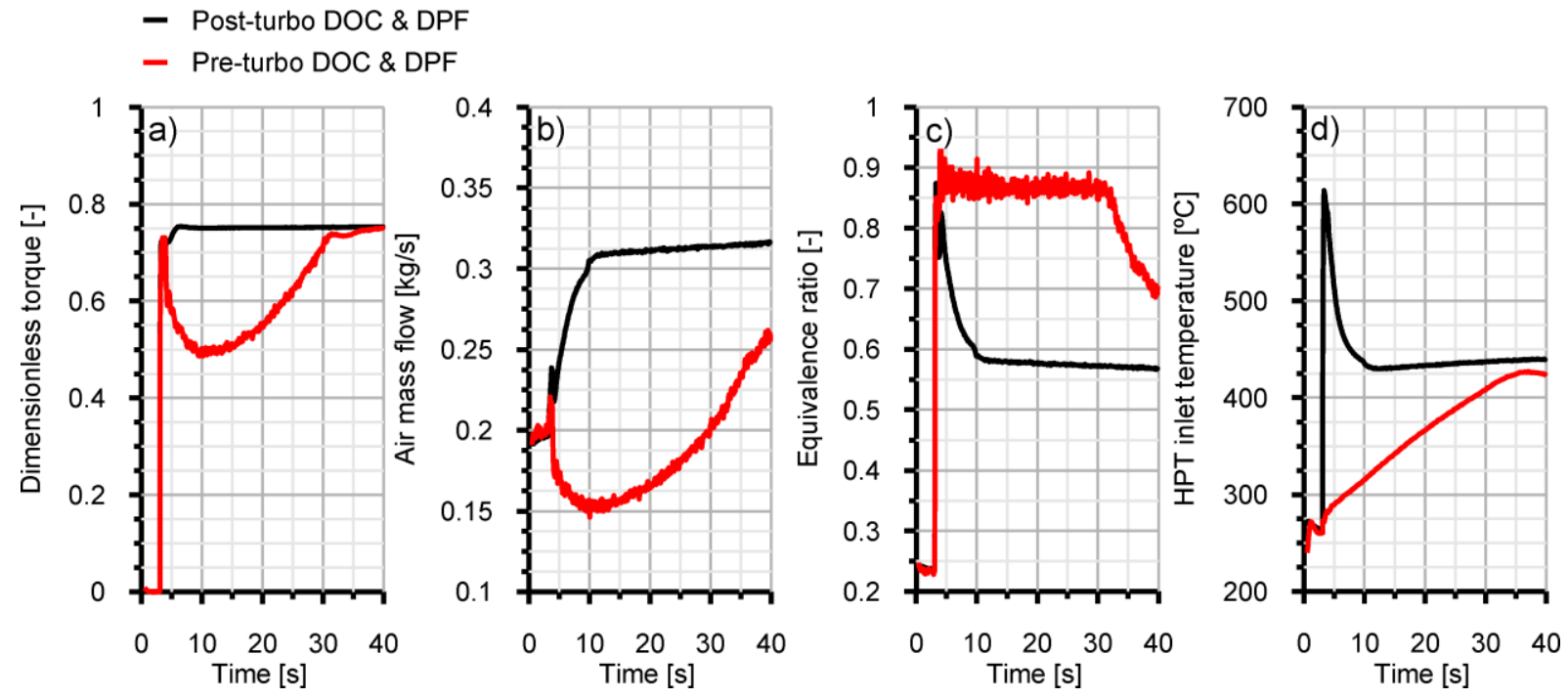

Figure 4.- Tip-in at $1200 \mathrm{r} / \mathrm{min}$ from $0 \%$ to $75 \%$ in engine load applying the same setting for EGR valve opening timing and maximum equivalence ratio.

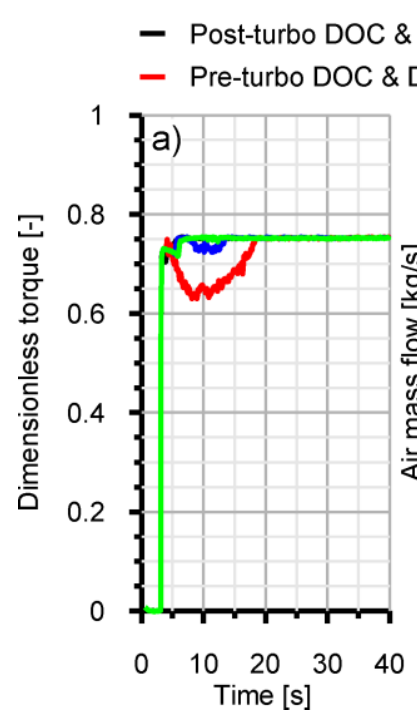

$$
\text { DPF (EGR delay: } 0.75 \mathrm{~s} \text { ) }
$$

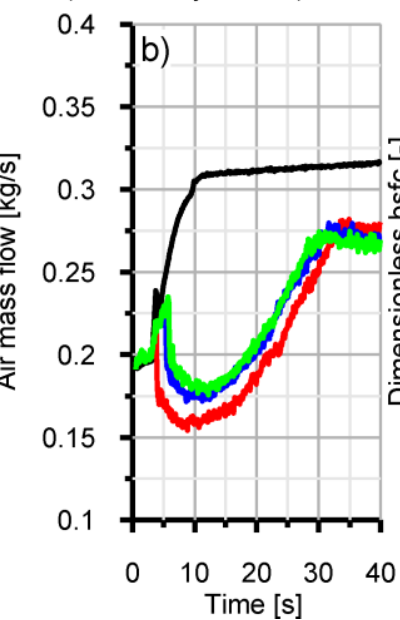

- Pre-turbo DOC \& DPF (EGR delay: $2.25 \mathrm{~s}$ )

- Pre-turbo DOC \& DPF (EGR delay: 2.75 s)

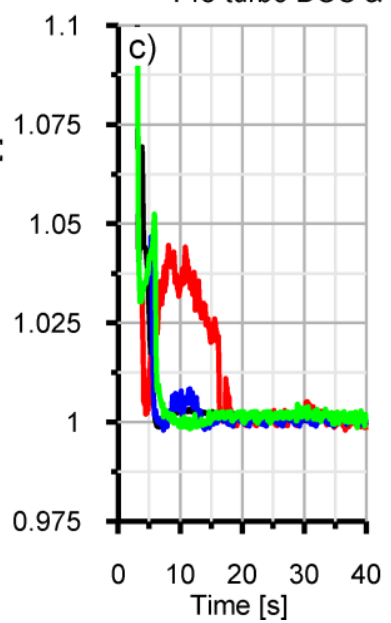

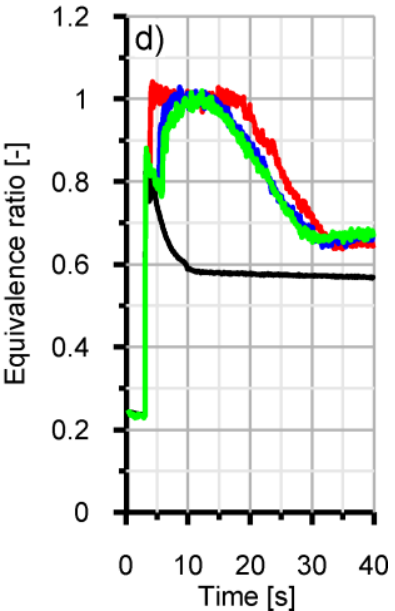

Figure 5.- Tip-in at $1200 \mathrm{r} / \mathrm{min}$ from $0 \%$ to $75 \%$ in engine load. Effect on engine performance of increase in maximum equivalence ratio and different EGR opening timing with a pre-turbo DOC and DPF architecture. 


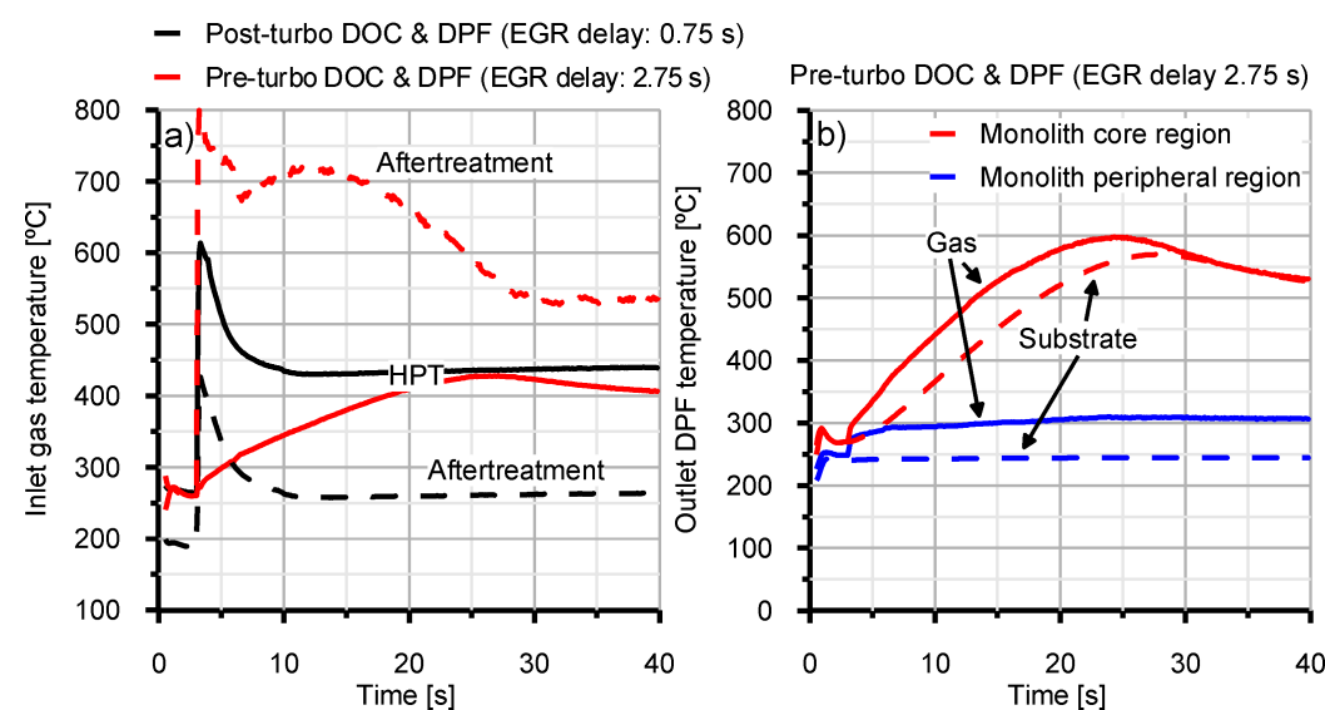

Figure 6.- Tip-in at $1200 \mathrm{r} / \mathrm{min}$ from $0 \%$ to $75 \%$ in engine load. Thermal transient in the DPF with a preturbo DOC and DPF configuration.
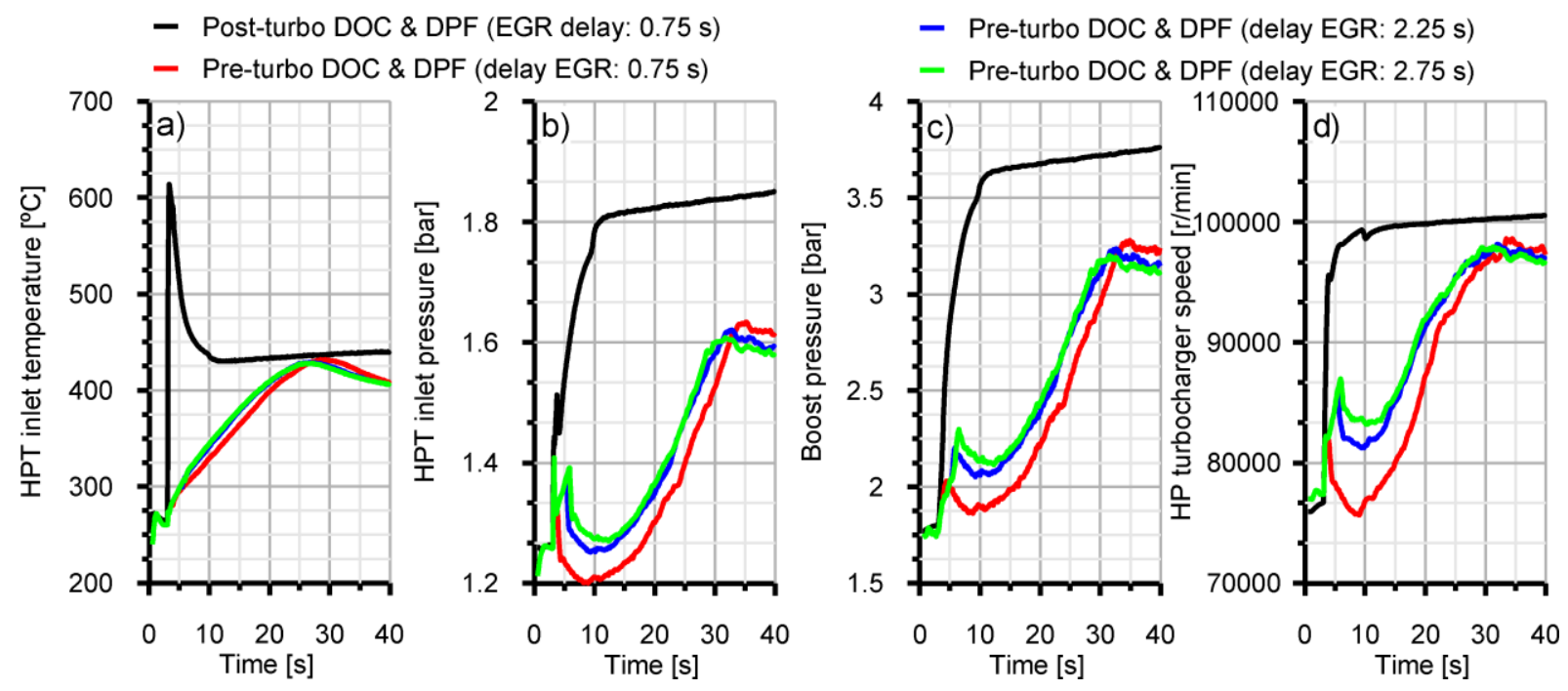

Figure 7.- Tip-in at $1200 \mathrm{r} / \mathrm{min}$ from $0 \%$ to $75 \%$ in engine load. HP turbocharger response as function of the exhaust manifold architecture. 


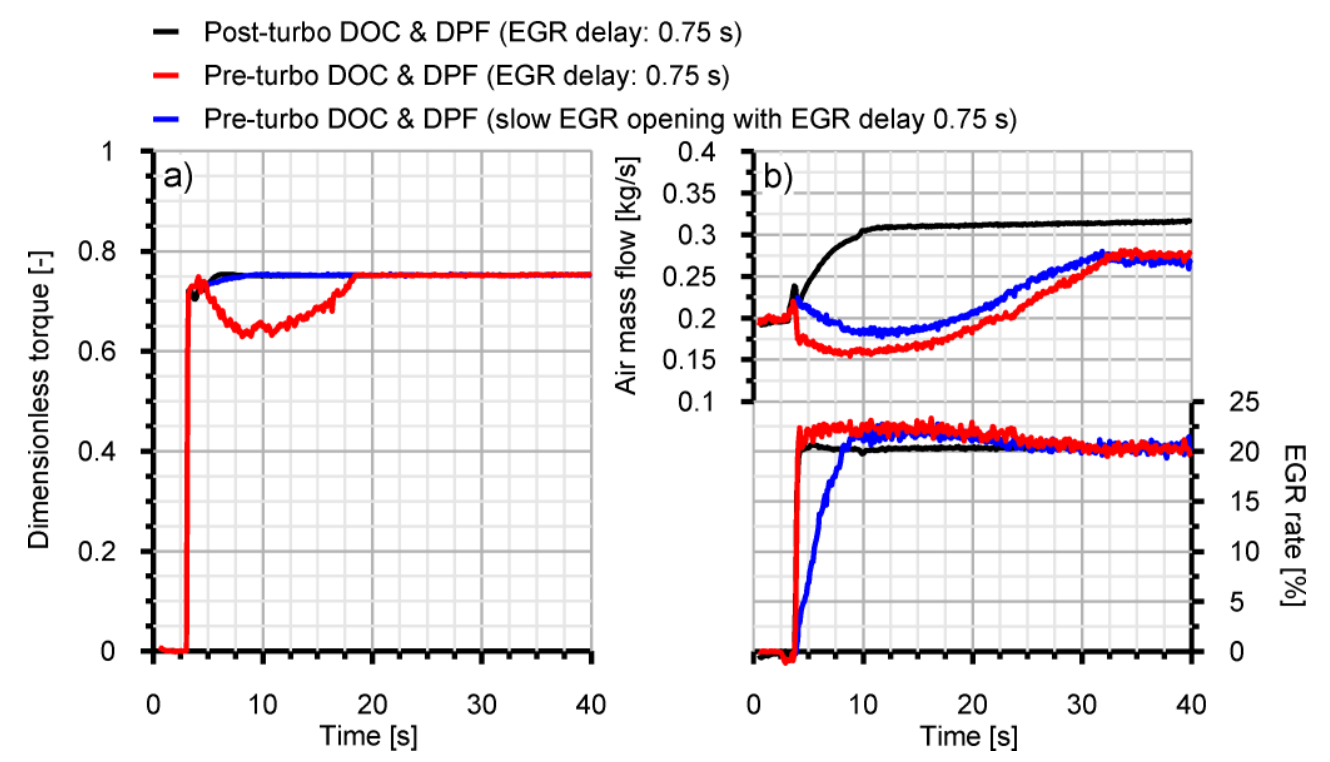

Figure 8.- Tip-in at $1200 \mathrm{r} / \mathrm{min}$ from $0 \%$ to $75 \%$ in engine load. Effect of EGR slow opening on engine torque and air mass flow.
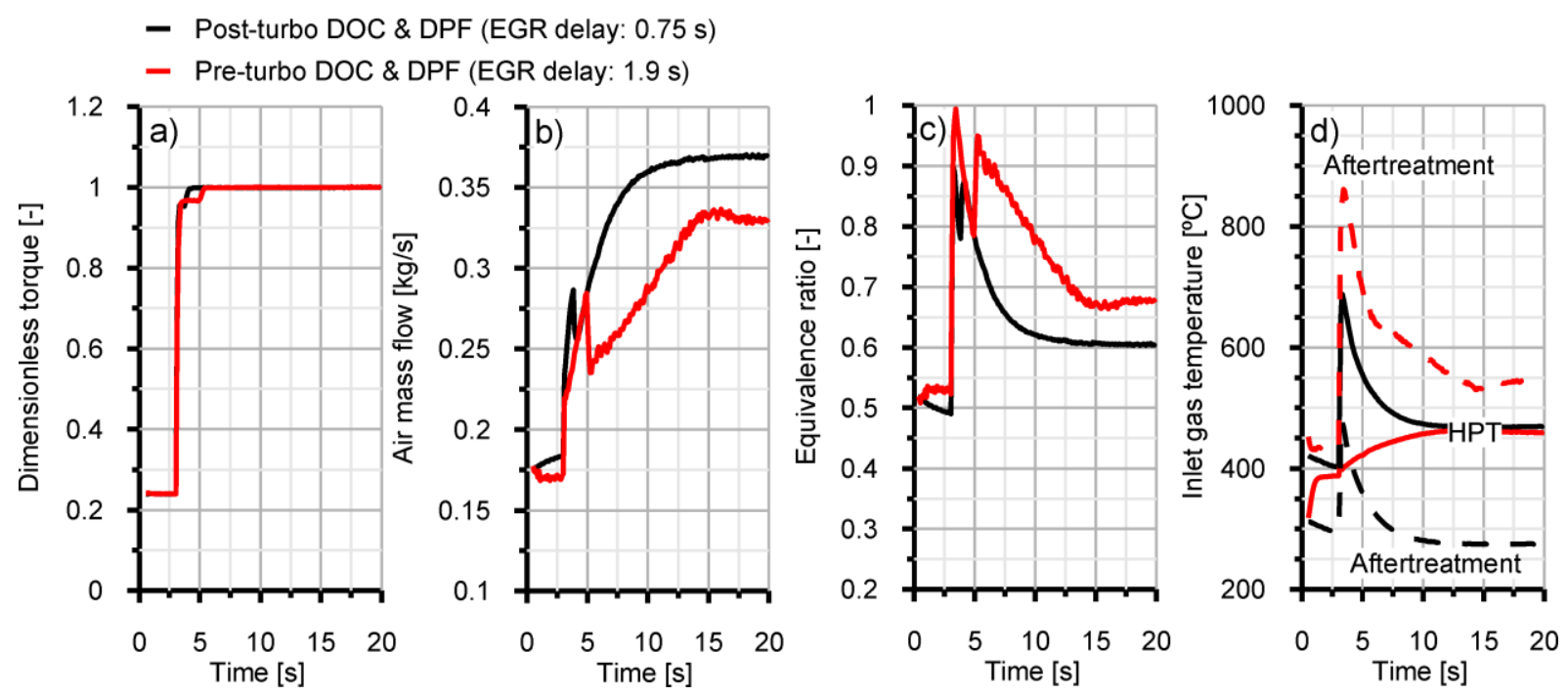

Figure 9.- Tip-in at $1200 \mathrm{r} / \mathrm{min}$ from $25 \%$ to $100 \%$ in engine load. Effect on engine response of a preturbo aftertreatment configuration. 
- Post-turbo DOC \& DPF

- Pre-turbo DOC \& DPF
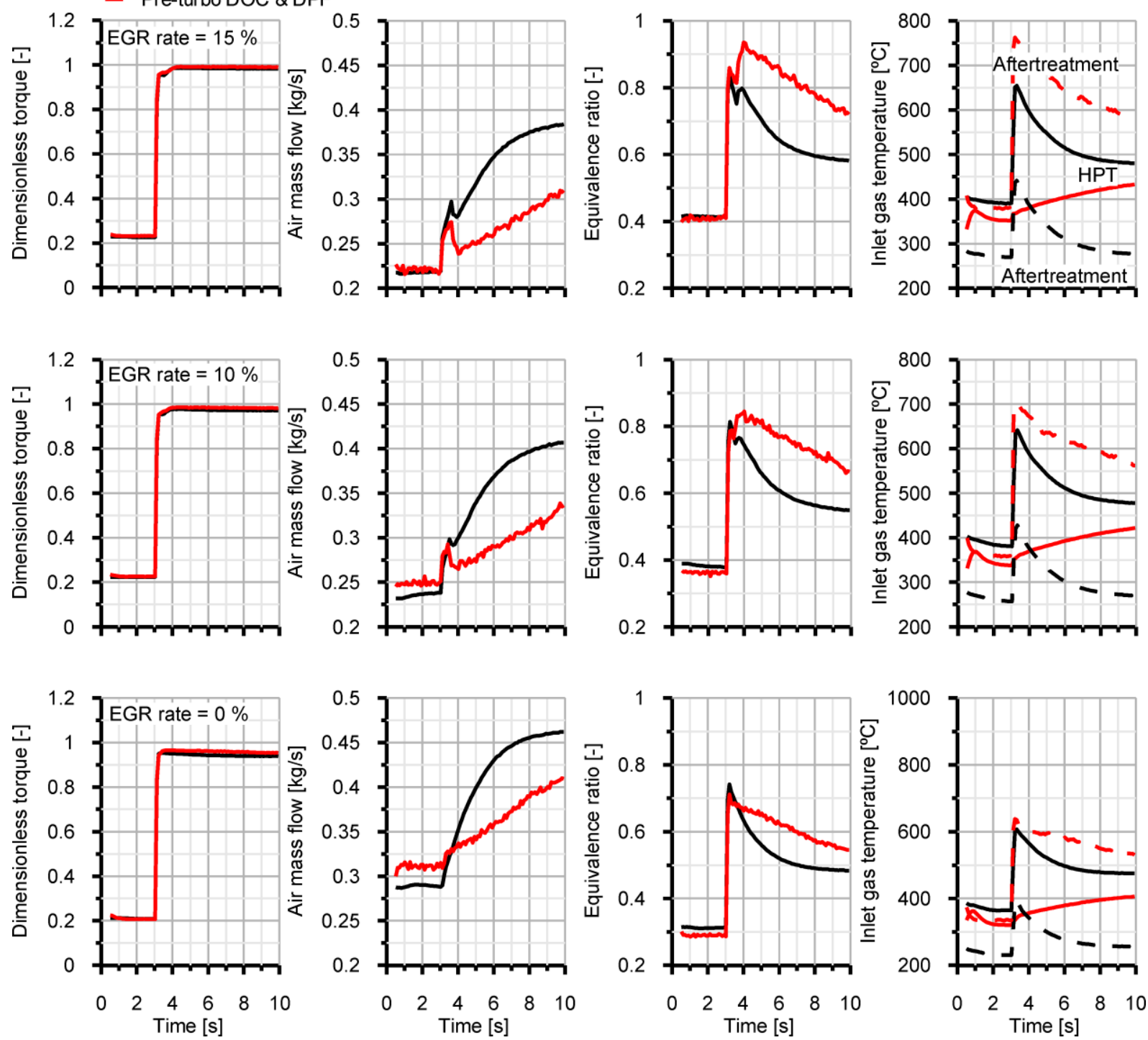

Figure 10.- Tip-in at 1200 r/min from $25 \%$ to $100 \%$ in engine load. Effect on engine response of a preturbo aftertreatment configuration under different EGR rate at steady state operation. 

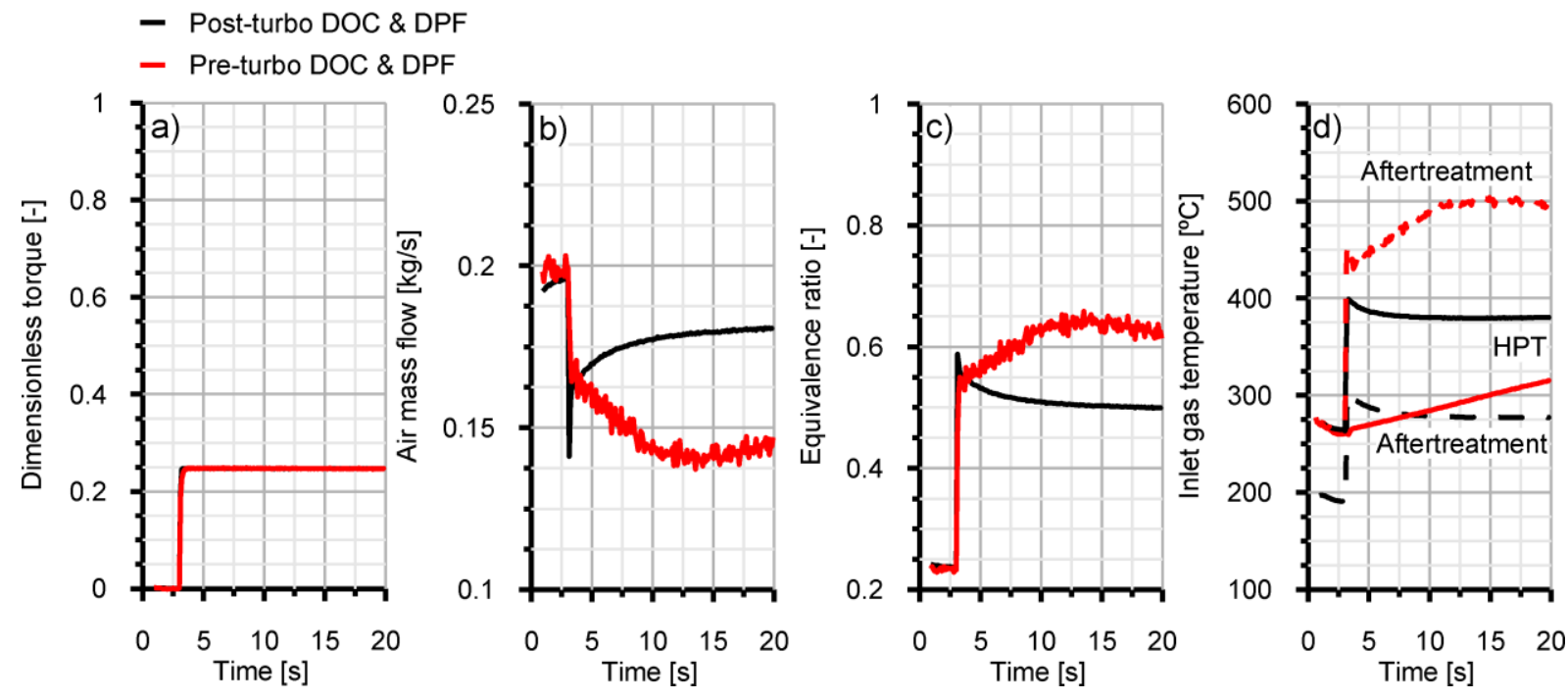

Figure 11.- Tip-in at $1200 \mathrm{r} / \mathrm{min}$ from $0 \%$ to $25 \%$ in engine load. Effect on engine response of a pre-turbo aftertreatment configuration.

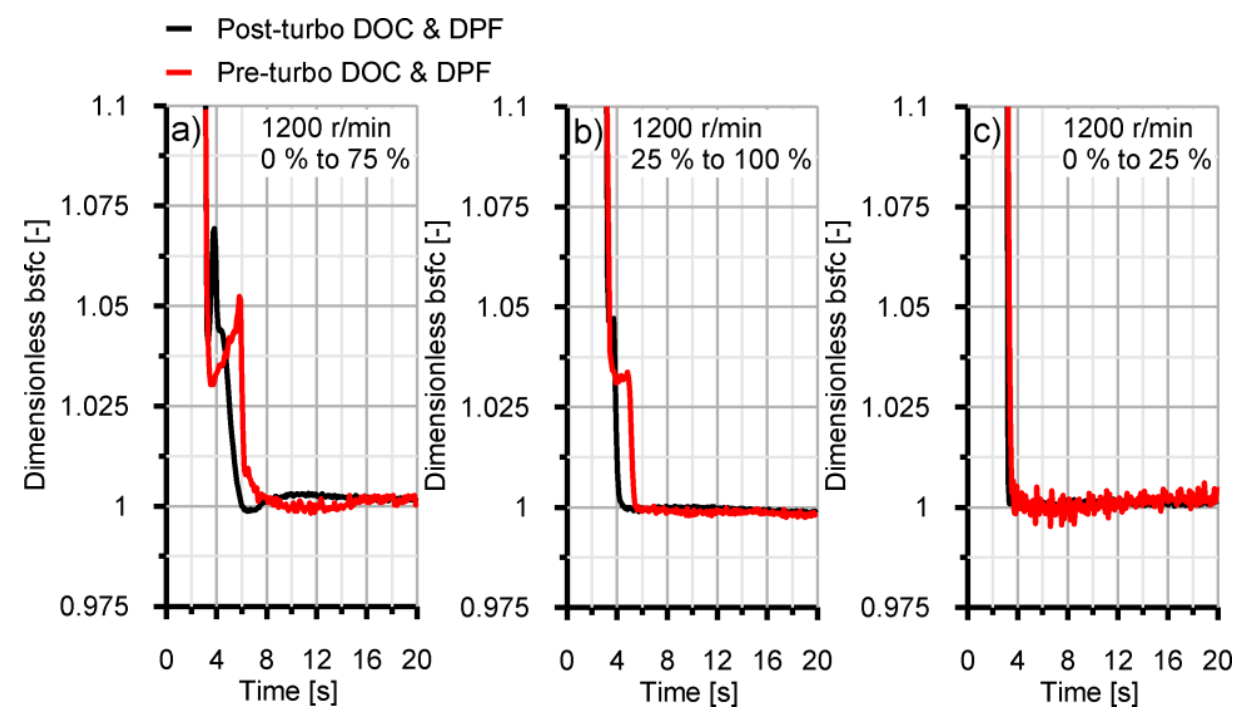

Figure 12.- Effect of pre-turbo aftertreatment configuration on bsfc during the different tip-in processes at $1200 \mathrm{r} / \mathrm{min}$. 